\title{
ГЕПАТОПРОТЕКТОРНОЕ ДЕЙСТВИЕ ПОЛИФЕНОЛОВ ПРИ ЭКСПЕРИМЕНТАЛЬНОЙ ТОКСИЧЕСКОЙ ПАТОЛОГИИ ПЕЧЕНИ, ВЫЗВАННОЙ ТИОАЦЕТАМИДОМ
}

Д. И. Дергачева ${ }^{1}$, О. И. Кляйн1${ }^{1}$, А. А. Мариничев ${ }^{1,2}$, Н. Н. Гесслер ${ }^{1}$, Е. С. Богданова ${ }^{3}$, М. С. Смирнова ${ }^{3}$, Е. П. Исакова ${ }^{1}$, Ю. И. Дерябина

${ }^{1}$ Институт биохимии имени А. Н. Баха, Федеральный исследовательский центр «Фундаментальные основы биотехнологии» РАН, Москва, Россия

${ }^{2}$ Московский химико-технологический университет имени Д. И. Менделеева, Москва, Россия

${ }^{3}$ Институт общей генетики имени Н. И. Вавилова, Москва, Россия

Неалкогольная жировая дисфункция печени сопровождает целый ряд заболеваний (диабет, ожирение, кардиоваскулярные болезни), а также может развиваться под действием лекарственных препаратов или токсических соединений. Актуальным направлением современной медицины является поиск эффективных средств профилактики и лечения жирового гепатоза. Целью работы было исследовать действие некоторых биологически активных природных полифенолов - стильбенов ресвератрола и пиносильвина, а также дигидрофлавонола дигидромирицетина — на функциональное состояние и гистологическую картину печени. В модели токсического гепатита, вызываемого введением гепатотоксиканта тиоацетамида, самцам крыс линии Wistar внутрижелудочно ежедневно вводили зондом эффективные дозы полифенолов на фоне добавления тиоацетамида к питьевой воде в концентрации 0,05\%. Все исследованные полифенолы способствовали стабилизации веса крыс и двухкратному достоверному (p < 0,05) снижению уровня прямого билирубина в сыворотке крови животных, получавших тиоацетамид. Гистологическое исследование печени подтвердило замедление воспалительных процессов и уменьшение кровоизлияний у животных, получавших полифенолы на фоне продолжающегося введения тиоацетамида в течение 30 дней. На основании полученных данных можно сделать выводы, что природные полифенолы класса дигидрофлавонолов (дигидромирицетин) и стильбенов (ресвератрол и пиносильвин) оказывают положительное воздействие на функции печени в модели экспериментального токсического гепатоза; исследованные полифенолы можно рассматривать в качестве потенциальных гепатопротекторов в составе комплексной терапии при заболеваниях печени.

Ключевые слова: полифенол, ресвератрол, дигидромирицетин, пиносильвин, тиоацетамид, стеатоз, гепатит, крыса

Финансирование: работа выполнена при поддержке Министерства образования и науки РФ (соглашение № 14.616.21.0083, уникальный идентификатор проекта RFMEFI61617X0083)

Благодарности: авторы признательны Центру высокоточного редактирования и генетических технологий для биомедицины (Москва) за помощь в методах исследования.

Информация о вкладе авторов: Д. И. Дергачева - проведение экспериментов по индукции токсического гепатита, проведение и анализ гистологических исследований, подготовка черновика рукописи; О. И. Кляйн - подготовка и проведение гистологических исследований, сбор, анализ и интерпретация данных; А. А. Мариничев - проведение экспериментов по индукции токсического гепатита, отбор проб крови экспериментальных животных, приготовление гистологических препаратов; Н. Н. Гесслер - проведение экспериментов по индукции токсического гепатита, отбор проб крови экспериментальных животных, сбор, анализ и интерпретация данных; Е. С. Богданова и М. С. Смирнова - анализ литературы, сбор, анализ и интерпретация данных; Е. П. Исакова - проведение экспериментов по индукции токсического гепатита, анализ литературы; Ю. И. Дерябина планирование исследования, анализ литературы, сбор, анализ и интерпретация данных.

Соблюдение этических стандартов: исследование одобрено этическим комитетом Института биохимии имени А. Н. Баха (протокол № 17 от 5 сентября 2019 г.). Содержание животных, все проведенные процедуры и экспериментальные протоколы соответствовали требованиям Минздрава России, а также директиве Совета Европейских сообществ от 24 ноября 1986 года (86/609/EЕC).

$\bigotimes$ Для корреспонденции: Мария Сергеевна Смирнова

ул. Москвина, 10-226, г. Химки, Московская обл., 141401; mbarbotko@ya.ru

Статья получена: 26.10.2019 Статья принята к печати: 17.11.2019 Опубликована онлайн: 27.11.2019

DOI: 10.24075 /vrgmu.2019.075

\section{HEPATOPROTECTIVE EFFECT OF POLYPHENOLS IN RATS WITH EXPERIMENTAL THIOACETAMIDE-INDUCED TOXIC LIVER PATHOLOGY}

Dergachova DI ${ }^{1}$, Klein $\mathrm{Ol}^{1}$, Marinichev $\mathrm{AA}^{1,2}$, Gessler NN¹ , Bogdanova ES ${ }^{3}$, Smirnova $\mathrm{MS}^{3} \otimes$, Isakova EP ${ }^{1}$, Deryabina $\mathrm{YI}^{1}$

${ }^{1}$ Bach Institute of Biochemistry, Federal Research Centre "Fundamentals of Biotechnology" RAS, Moscow, Russia

2 Dmitry Mendeleev University of Chemical Technology, Moscow, Russia

${ }^{3}$ Vavilov Institute of General Genetics, Moscow, Russia

Non-alcoholic fatty liver disease is associated with a number of disorders (diabetes, obesity, cardiovascular diseases), and can also be induced by drugs or toxic compounds. Recently the important branch of medicine is the search for effective means of prevention and treatment of fatty hepatosis. Our work was aimed to study the effect of some biologically active natural polyphenols (resveratrol and pinosylvin stilbenes as well as dihydromyricetin dihydroflavonol) on the function and histologic features of the liver. In the experimental model of thioacetamide-induced toxic hepaptitis, the male rats of the Wistar line daily received the effective doses of polyphenols intragastically by gavage together with $0.05 \%$ thioacetamide added to drinking water. All studied polyphenols contributed to stabilization of rat weight and a two-fold significant $(p<0.05)$ decrease in the level of direct bilirubin in the blood serum of animals treated with thioacetamide. Histological analysis of the liver confirmed a decrease in inflammation and hemorrhage in animals treated with polyphenols amid continued administration of thioacetamide for 30 days. Based on the data obtained, it can be concluded that the natural polyphenols which belong to the classes of dihydroflavonols (dihydromyricetin) and stilbenes (resveratrol and pinosylvin) have a positive effect on liver function in the experimental model of toxic hepatosis. The studied polyphenols can be considered as potential hepatoprotective drugs used as a part of the liver diseases complex therapy.

Keywords: polyphenol, resveratrol, dihydromyricetin, pinosylvin, thioacetamide, steatosis, hepatitis, rat

Funding: the study was supported by the Ministry of Education and Science of the Russian Federation (agreement № 14.616.21.0083, unique project ID: RFMEFI61617X0083). Acknowledgement: we thank to the Center for Precision Genome Editing and Genetic Technologies for Biomedicine (Moscow) for the genetic research methods. Author contribution: Dergachova DI — conducting experiments on toxic hepatitis induction, histological analysis, manuscript draft preparation; Klein OI — histological studies, data acquisition and analysis; Marinichev AA - experiments on toxic hepatitis induction, blood sample collection from experimental animals, preparation of histological samples; Gessler NN — conducting experiments on toxic hepatitis induction, blood sample collection from experimental animals, data acquisition and analysis; Bogdanova ES, Smirnova MS — literature analysis, data acquisition and analysis; Isakova EP — conducting experiments on toxic hepatitis induction, literature analysis; Deryabina YI — experiment planning, literature analysis, data acquisition and analysis.

Compliance with ethical standards: the study was approved by the Ethics Committee of Bach Institute of Biochemistry RAS (protocol № 17 dated September $5,2019)$. The animals' care as well as all procedures and experimental protocols complied with the Ministry of Health of the Russian Federation requirements and to the Council Directive of November 24, 1986 (86/609/EEC).

$\triangle$ Correspondence should be addressed: Maria S. Smirnova Moskvina, 10-226, Khimki, Moscow Region, 141401; mbarbotko@ya.ru

Received: 26.10.2019 Accepted: 17.11.2019 Published online: 27.11.2019

DOI: $10.24075 /$ brsmu.2019.075 
Болезни печени включают широкий спектр патологий: от жирового гепатоза (стеатоза) и гепатита до цирроза печени и гепатоцеллюлярной карциномы. Они широко распространены во всем мире и имеют высокую социальную значимость [1]. Печеночная недостаточность, особенно ее тяжелая форма, вызванная циррозом печени, занимает 12-е место среди причин смертельных случаев в мире [2]. Циррозы не только приводят к нарушениям функции печени, но и вызывают развитие печеночного энцесралопатического синдрома, представляющего собой нарушение когнитивных функций и психомоторики. Печеночный синдром может послужить причиной инвалидизации больного [3]. За последние 10 лет неалкогольная жировая дисфункция печени стала основным типом ее хронических поражений: она выявлена более чем у $30 \%$ населения [4]. Развитие жирового гепатоза статистически ассоциировано с сахарным диабетом, сердечно-сосудистыми заболеваниями, ожирением. Его возникновение провоцируют применение лекарственных препаратов и воздействие токсических соединений. Выявлена связь стеатоза с другими хроническими заболеваниями, такими как сонное апное, колоректальный рак, остеопороз, псориаз и эндокринные нарушения [5]. Неалкогольная жировая дистрофия печени представляет собой неспецифическую реакцию гепатоцитов на токсическое воздействие. Основной характеристикой этого состояния является избыточное накопление жира в печени. При сильной жировой дистрофии можно наблюдать жировые кисты и разрастание соединительной ткани, что приводит к функциональным нарушениям печени и связанным с ними системным патологиям.

Множество сигнальных и метаболических путей, участвующих в регуляции работы печени, дают возможность выбора терапевтических мишеней [6]. В качестве гепатопротекторных соединений в составе комплексной терапии применяют различные агенты: антибиотики (неомицин, паромицин, метронидазол, ванкомицин, рифаксимин) [7] и дисахариды (лактулоза, лактитол) с низкой способностью К всасыванию [8], природные аминокислоты и метаболиты азотного обмена (орнитина аспартат, аминокислоты с разветвленной цепью) [9], модуляторы бактериальной кишечной микрофллоры (пробиотики, синбиотики) [10], производные желчных кислот и $\beta$-агонисты рецепторов тиреоидных гормонов [11]. Однако существующие в настоящее время средства профилактики и лечения патологий печени различной степени выраженности и этиологии включают в основном симптоматические препараты довольно широкого диапазона действия, значительная часть которых либо не рекомендована для длительного применения, либо не разрешена к использованию в ряде стран. Среди лекарственных средств с высокой доказанной эффективностью и безопасностью длительного применения в качестве гепатопротекторов можно выделить эссенциальные фосфолипиды (ЭФЛ), урсодезоксихолевую кислоту (УДХЛ), препараты расторопши, адеметионин [12].

Природные полифенолы широко применяют в настоящее время в качестве антиоксидантных фармакологических субстанций, оказывающих общее противовоспалительное, нейро- и кардиопротекторное действия, моделирующих аутофагию и защищающих митохондрии от патологических событий, индуцируя сигнальные пути выживания клеток [13]. Успех применения полифенолов для лечения заболеваний, имеющих сложносоставную этиологию (нейродегенеративных расстройств различного происхождения, аутоиммунных, аллергических, онкологических и прионных), связан с их непосредственным влиянием на клетки защитных систем организма и индукцией апоптоза клеток основных тканей [14]. Полифенолы растительного происхождения оказывают влияние на окислительный стресс, липидный обмен, инсулинорезистентность и воспаление, которые являются наиболее важными патологическими процессами в этиологии заболеваний печени [1]. Показано положительное действие некоторых полифенолов на функциональное состояние печени в модели токсического гепатита индуцированного различными гепатотоксикантами. Так, природный флавоноид кверцетин защищал печень от диссункции, индуцированной тетрахлорметаном $\left(\mathrm{CCl}_{4}\right)$. Механизм реализации его эффекта авторы связывали с антиоксидантным действием, а также с подавлением ряда реакций при участии NF-кB, что приводило к уменьшению уровня секреции воспалительных цитокинов печени [15]. Еще один фрлавоноид, пуэрарин, также заметно ослаблял последствия $\mathrm{CCl}_{4}$-индуцированной гепатотоксичности за счет снижения продукции активных форм кислорода (АФК), активации антиоксидантной ферментной системы и регулирования экспрессии генов, ответственных за биосинтез и метаболизм липидов в печени [16]. Флавоноид байкалин, выделенный из шлемника (Scutellaria radix), оказался эффективным в защите печени от ацетаминофениндуцированного токсического повреждения за счет подавления сигнализации внеклеточного сигналрегулируемого киназного пути [17].

Введение тиоацетамида (ТАА) приводит к индукции фиброза и цирроза печени у крыс и мышей. Через две недели после начала введения ТАА в ряде исследований наблюдали значительное повышение активности печеночных аминотрансфераз (аланинаминотрансферазы (АЛТ) и аспартатаминотрансферазы (АСТ)), указывающее на развитие патологического процесса. К концу четвертой недели активность АСТ и АЛТ снижалась до нормальных значений на фоне увеличения содержания коллагена в ткани печени [18]. Окислительный стресс считают основным фактором в ТАА-индуцированном фииброзном перерождении печени, вызванном токсическим метаболитом тиоацетамид-Sоксидом, образующимся при биотрансформации ТАA ферментами семейства цитохром P450 (СYP1A2, CYP2C6, CYP2Е1, СҮР3А2) и микросомальными ФАД-содержащими монооксигеназами $[19,20]$. Согласно опубликованным данным, ресвератрол значительно снижал повреждения печени, вызванные ТАА. Механизм его действия обусловлен снижением интенсивности окислительного стресса, подавление NF-кB-зависимого каскада реакций и апоптоза [21]

Целью представленной работы было исследовать потенциальное гепатопротекторное действие полисенолов стильбеновой природы - ресвератрола (РСВ) и пиносильвина (ПС) - и дигидрофрлавонола дигидромирицетина (ДГМ) на функциональное состояние и гистологическую картину печени в модели токсического гепатита крыс, вызываемого ТАA.

\section{МАТЕРИАЛЫ И МЕТОДЫ}

Эксперименты проводили на самцах белых крыс линии Wistar (начальный вес животных составлял 190-230 г), полученных из питомника "Столбовая» (Московская обл.) с условиями содержания, соответствующими требованиям GLP. Животных на протяжении эксперимента содержали в 
условиях вивария с естественным световым режимом (12 ч день, 12 ч ночь) на полнорационной сбалансированной по содержанию питательных веществ диете для лабораторных животных, согласно ГОСТ Р502580092. Работу осуществляли в соответствии с требованиями Руководства по проведению доклинических исследований (в 2-х частях, под редакцией А. Н. Миронова (действующая редакция)) и необходимых нормативных документов.

Для индукции токсического повреждения печени и развития печеночной патологии животным ежедневно алиментарным путем вводили водный 0,05\%-й раствор ТАА, который показал высокую эффективность при разработке модели печеночной патологии [18, 20]. Введение ТАА приводит к индукции фиброза и цирроза печени у крыс и мышей.

Животных разделили на группы по 10 животных:

1 - группа интактных животных, которых содержали на обычном пищевом рационе;

2 - группа контрольных животных, получавших с питьем 0,05\%-й ТАA;

3 - экспериментальная группа, получавшая с питьем 0,05\%-й ТАА на фоне введения РСВ (15 мг на 1 кг веса перорально);

4 - экспериментальная группа, получавшая с питьем 0,05\%-й ТАA на фоне введения ДГМ (10 мг на 1 кг веса перорально);

5 - экспериментальная группа, получавшая с питьем 0,05\%-й ТАА на фоне введения ПС (5 мг на 1 кг веса перорально).

Введение животным ТАА проводили в течение 30 дней. Осмотр животных проводили ежедневно, взвешивание осуществляли каждые три дня. Полифенолы были выделены и очищены из растительного сырья (биоматериалов хвойных пород, доступных на территории РФ). Полифенолы вводили в виде раствора в водном 2\%-м крахмальном геле каждый день внутрижелудочно через зонд, после приема пищи, из расчета не более 0,4 мл на каждое животное. Отбор крови и образцов печени животных для биохимических и гистологических исследований проводили на 10-е, 20-е и 30-е сутки эксперимента. Образцы тканей печени и крови отбирали немедленно после вскрытия. Полученные образцы сыворотки крови исследовали с помощью биохимического анализатора AU 480 (BeckmanCoulter; США) на содержание прямого билирубина, активности ферментов (аминотрансфераз АСТ и АЛТ). Биохимический анализ крови экспериментальных животных выполняли на базе независимой ветеринарной лаборатории «ШансБио» (участник Федеральной системы внешнего контроля качества лабораторных исследований МЗ РФ ФСВОК, код участника 10705) с применением анализаторов AU 480 (BeckmanCoulter; США), биохимической системы BA 400 (BioSystems; Испания) и Abacus Vet 4 (Diatron; Австрия). Индекс печени определяли как соотношение массы органа к массе тела (в \%). Для гистологических исследований брали кусочки печени из нижней части правой доли. Гистологические препараты (тонкие срезы) получали путем изготовления парафинированных микросрезов согласно методике, описанной в работе [22]. Приготовление препаратов включало следующие этапы.

1. Подготовка органов для заливки в раствор 4\%-го параформальдегида (ПФА) в фосфратно-солевом буфере (ФСБ). Отобранные при вскрытии органы крыс помещали в планшеты с разлитым 4\%-м ПФА на 30 мин. Каждые 30 мин производили трехкратную смену 4\%-го ПФА на новый раствор, после чего оставляли на 24 ч при температуре $+4^{\circ} \mathrm{C}$.
2. Подготовка органов к заливке в уплотняющие среды по следующей схеме: а) промывание 3 раза ФСБ по 30 мин при $+4{ }^{\circ} \mathrm{C}$; б) инкубация в 70\%-м этаноле, 3 смены по 30 мин; в) инкубация в 80\%-м этаноле 40 мин; г) инкубация в смеси: 82\% этанол-бутанол (3 : 1) 40 мин; д) инкубация в смеси: 96\% этанол-бутанол (1 : 1) 50 мин; е) инкубация в смеси: 100\% этанол (абсол.) - бутанол (1: 3) 50 мин; ж) инкубация в бутаноле I 1 4; 3) инкубация в бутаноле II - 1 4.

3. Заливка органов в парафин. Использовали парафин температуры $+60{ }^{\circ} \mathrm{C}$, заливали его в подготовленную и нагретую форму из фольги и помещали туда образец. Сушили блоки в течение 10-12 ч.

4. Приготовление срезов для окрашивания. Охлажденные парафиновые блоки закрепляли на деревянном блоке при помощи растопленного парафина. Срезы делали на микротоме санном МС-2 (ХЗ «Точмедприбор»; Россия). Затем получившиеся срезы крепили на предметное стекло и помещали в сушилку на 30 мин при температуре $+40^{\circ} \mathrm{C}$.

5. Покраска срезов. Срезы перед окрашиванием освобождали от парафина с помощью толуола или ксилола. Окрашивание срезов проводили в системе «гематокислин-эозин». После окрашивания на срезы наносили Immuno Mount-DABCO ${ }^{\mathrm{TM}}$ (Genetex; Канада) и сверху помещали покровное стекло.

Статистические расчеты производили на персональном компьютере с использованием программного пакета STATISTICA 6.0 (Dell; CШA). Данные представляли как среднюю арифметическую величину и стандартную ошибку средней $(M \pm m)$. Для оценки различий параметров между группами животных использовали параметрический $t$-критерий Стьюдента. Различия считали значимыми при $p<0,05$.

\section{РЕЗУЛЬТАТЫ ИССЛЕДОВАНИЯ}

Оценка динамики веса животных показала, что для интактных животных (группа 1) было характерно увеличение массы тела на протяжении всего периода эксперимента (рис. 1, 1). На фоне введения ТАА независимо от введения полифенолов вес животных заметно снижался в первую неделю эксперимента. Введение полисенолов обеспечило положительную тенденцию увеличения массы животных по сравнению с контрольной группой, начиная с третьей недели, что могло свидетельствовать о позитивном воздействии полифенолов на функции печени. К концу эксперимента индекс печени (соотношение массы органа и массы тела животного) возрастал с 3,65 \pm 0,2 у интактных животных до 5,1 \pm 0,3 у животных контрольной группы, получавших ТАА. В группах, получавших полифенолы наряду с ТАA, индекс печени составлял 4,5 $\pm 0,19,4,6 \pm 0,23$ и 4,4 \pm 0,16 для групп животных, которым вводили РСВ, ДГМ и ПС соответственно. Снижение индекса печени у животных, получавших полисенолы, свидетельствовало о снижении патологических изменений, вызываемых введением ТАА.

Анализ динамики биохимических показателей крови экспериментальных животных, получающих ТАА, показал, что уровень билирубина в крови увеличивался почти в 10 раз, в то время как введение полифенолов уменьшало этот показатель в 2-4 раза (табл. 1). Следует отметить, что эфффект снижения уровня билирубина в сыворотке крови проявлялся на протяжении всего периода введения полифенолов. Содержание общего белка и глюкозы несколько снижалось во всех группах, получавших ТАA, независимо от введения полифенолов (достоверных различий нет, данные не представлены). 


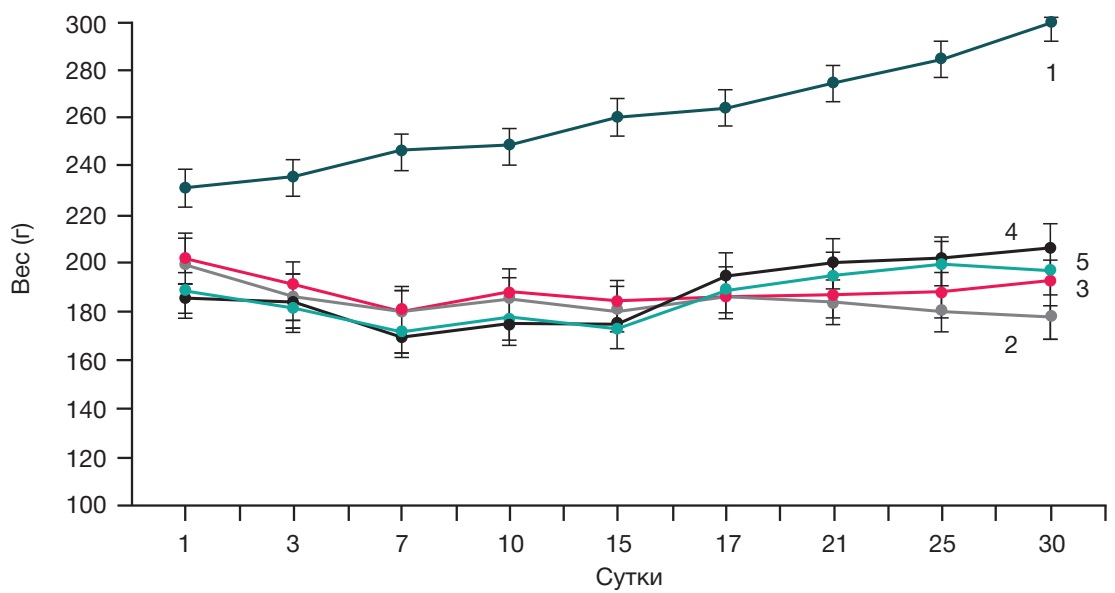

Рис. 1. Динамика изменения веса животных в ходе эксперимента: 1 - интактная группа; 2 - контрольная группа, получавшая ТАА; 3-5 - группы животных, получавших наряду с ТАА полифенолы РСВ, ДГМ и ПС соответственно

Активность АСТ достоверно повышалась $(p<0,05)$ в сыворотке крови животных всех групп, получавших ТАА, по сравнению с контролем (рис. 2А). Почти двукратное повышение АСТ у животных контрольной группы к 20-му дню и далее некоторое снижение к 30-му дню эксперимента характерно для этой модели гепатотоксичности и хорошо согласуется с данными других авторов [18, 21]. На фоне полифенолов показатели АСТ были ниже, а к концу эксперимента в группах, получавших РСВ и ПС, можно было наблюдать достоверное снижение этого показателя по сравнению с контрольной группой (рис. 2А).

Активность АЛТ при введении ТАА в контрольной группе достоверно повышалась $(p<0,05)$ на 40\% только после 20-го дня эксперимента (рис. 2Б). Было отмечено также увеличение активности АЛТ в середине эксперимента у животных, получавших РСВ на фоне ТАА (около 30\%), и небольшое повышение (20\%) у животных с введением ПС к 30-му дню эксперимента. В группе, получавшей ДГМ, значения АЛТ на протяжении всего периода наблюдения не отличались от таковых у интактных животных. К концу эксперимента показатели АЛТ нормализовались у животных группы, получавшей РСВ (рис. 2Б).

На следующем этапе работ были проанализированы гистологические срезы печени животных всех исследованных экспериментальных групп. Гепатоциты интактных животных характеризовались нормальной цитоморфологией с хорошо выраженными ядрами и умеренным полиморфизмом ткани (рис. ЗА). Интоксикация гепатотоксикантом ТАA приводила к появлению диапедезных кровоизлияний (рис. ЗБ) и возникновению мелкокапельной жировой дистрофии. Полученная нами гистологическая картина соответствовала известным симптомам патологии печени после действия ксенобиотиков (TAA и $\mathrm{CCl}_{4}$ ) [23]. Введение животным полифенолов (рис. ЗГ-Е) предотвращало существенную деградацию ткани печени: нарушение структуры гепатоцитов, появление гематом и очагов воспаления, содержащих мелкоклеточные образования (рис. ЗГ-Е).

\section{ОБСУЖДЕНИЕ РЕЗУЛЬТАТОВ}

Положительное влияние целого ряда природных полифенолов на индуцированные гепатотоксикантами патологии печени хорошо известно. Так, флавоноид кверцетин оказывал защитное действие при индуцированном $\mathrm{CCl}_{4}$ токсическом гепатите у мышей [15]. Полисенол диеккол из бурой водоросли Eisenia bicyclis (Kjellman) Setchell защищал печень мышей от $\mathrm{CCl}_{4}$-индуцированного разрушения через регуляцию генов, отвечающих за экспрессию апоптических белков Baх и Bcl-xl [24]. В другой работе полифенол изорамнетин3-О-галактозид, изолированный из полыни волосовидной (Artemisia capillaris Thunberg), также оказывал положительное действие при $\mathrm{CCl}_{4}$-индуцированной патологии печени через уменьшение уровня фоссфорилированной с-JNK, внеклеточной сигнал-регулирующей киназы (ERK) и p38 MAPK [25]. Флавоноид байкалин оказывал значительный защитный эффект при ацетаминофен-индуцированном гепатите у мышей [17]. В используемой в нашей работе модели токсического повреждения печени, индуцируемого TAА, защитное влияние полифенолов исследовано только на примере полисенола стильбенового ряда РСВ. В недавней работе [21] было продемонстрировано индуцированное РСВ ингибирование воспалительного процесса и окислительного стресса в тканях печени крыс за счет снижения уровня экспрессии NF-кB и CYP2E1 и увеличения апоптоза некротизированных гепатоцитов. Кроме того, в работе была показана стабилизация биохимических показателей крови (АЛТ и АСТ) и нормализация тканевой архитектуры печени опытных животных, получающих РСВ (10 мг на кГ веса животных). Учитывая эти данные, можно предположить, что в наших исследованиях имеет место похожий механизм действия

Таблица 1. Изменение уровня билирубина в сыворотке крови крыс в ходе эксперимента

\begin{tabular}{|c|c|c|c|c|c|}
\hline \multirow{2}{*}{ Период } & \multicolumn{5}{|c|}{ Билирубин прямой, мкмоль/л } \\
\cline { 2 - 6 } & Интактная & Контрольная & РСВ & дГМ & ПС \\
\hline 10 дней & $0,4 \pm 0,1$ & $4,9 \pm 0,5^{*}$ & $1,1 \pm 0,2^{*},{ }^{* *}$ & $1,5 \pm 0,6^{*},{ }^{* *}$ & $1,2 \pm 0,6^{*},{ }^{* *}$ \\
\hline 20 дней & $0,4 \pm 0,2$ & $4,4 \pm 0,5^{*}$ & $2,0 \pm 0,8^{*},{ }^{* *}$ & $1,3 \pm 0,5^{*},{ }^{* *}$ & $2,5 \pm 0,2^{*},{ }^{* *}$ \\
\hline 30 дней & $0,45 \pm 0,2$ & $4,2 \pm 1,1^{*}$ & $1,1 \pm 0,1^{*, * *}$ & $2,4 \pm 0,6^{*},{ }^{* *}$ & $1,5 \pm 0,7^{*},{ }^{* *}$ \\
\hline
\end{tabular}

Примечание: * $-p<0,05$ по отношению к соответствующим показателям интактной группы; ** $-p<0,05$ по отношению к соответствующим показателям контрольной группы. 
A
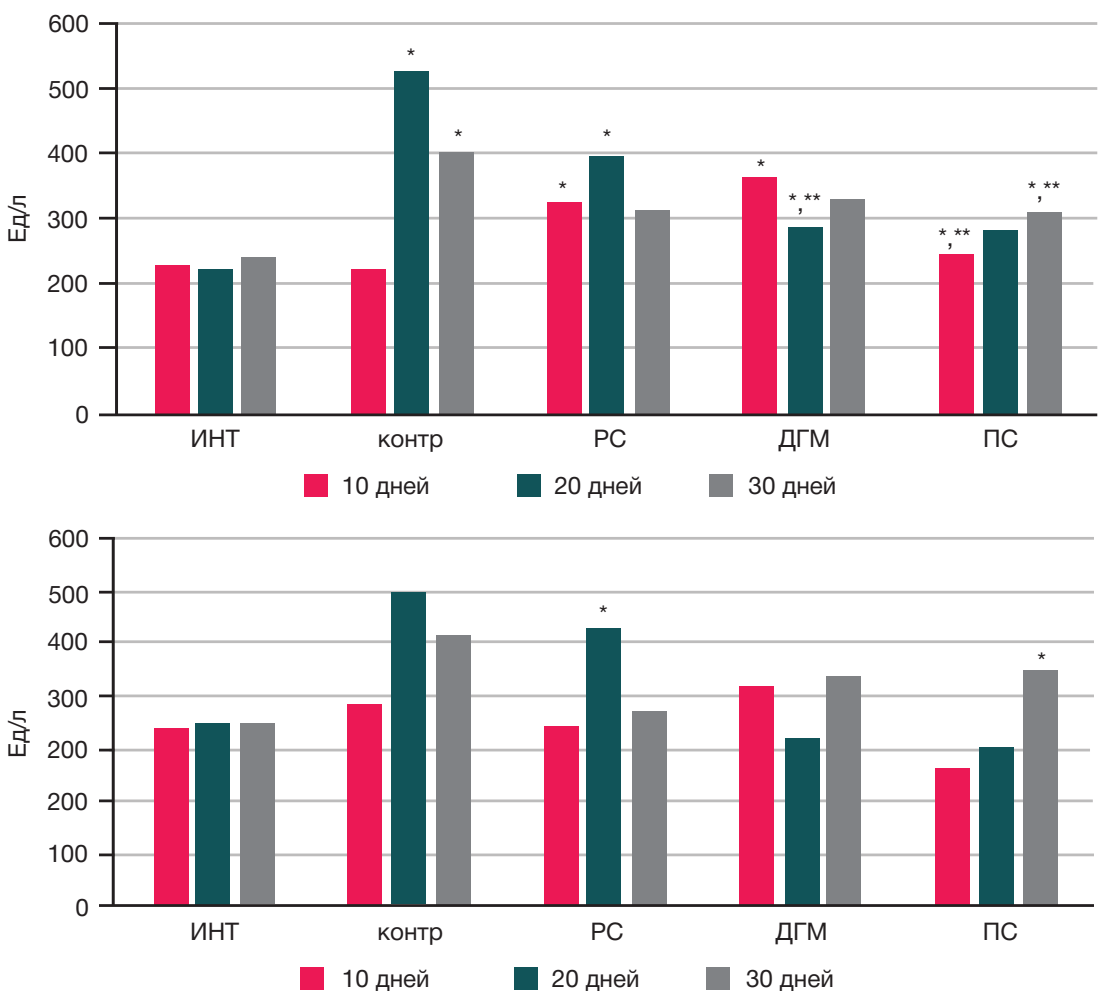

Рис. 2. Изменение АСТ (А) и АЛТ (Б) в сыворотке крови крыс в процессе эксперимента. * $-p<0,05$ по отношению к соответствующим показателям интактной группы; ** $-p<0,05$ по отношению к соответствующим показателям контрольной группы
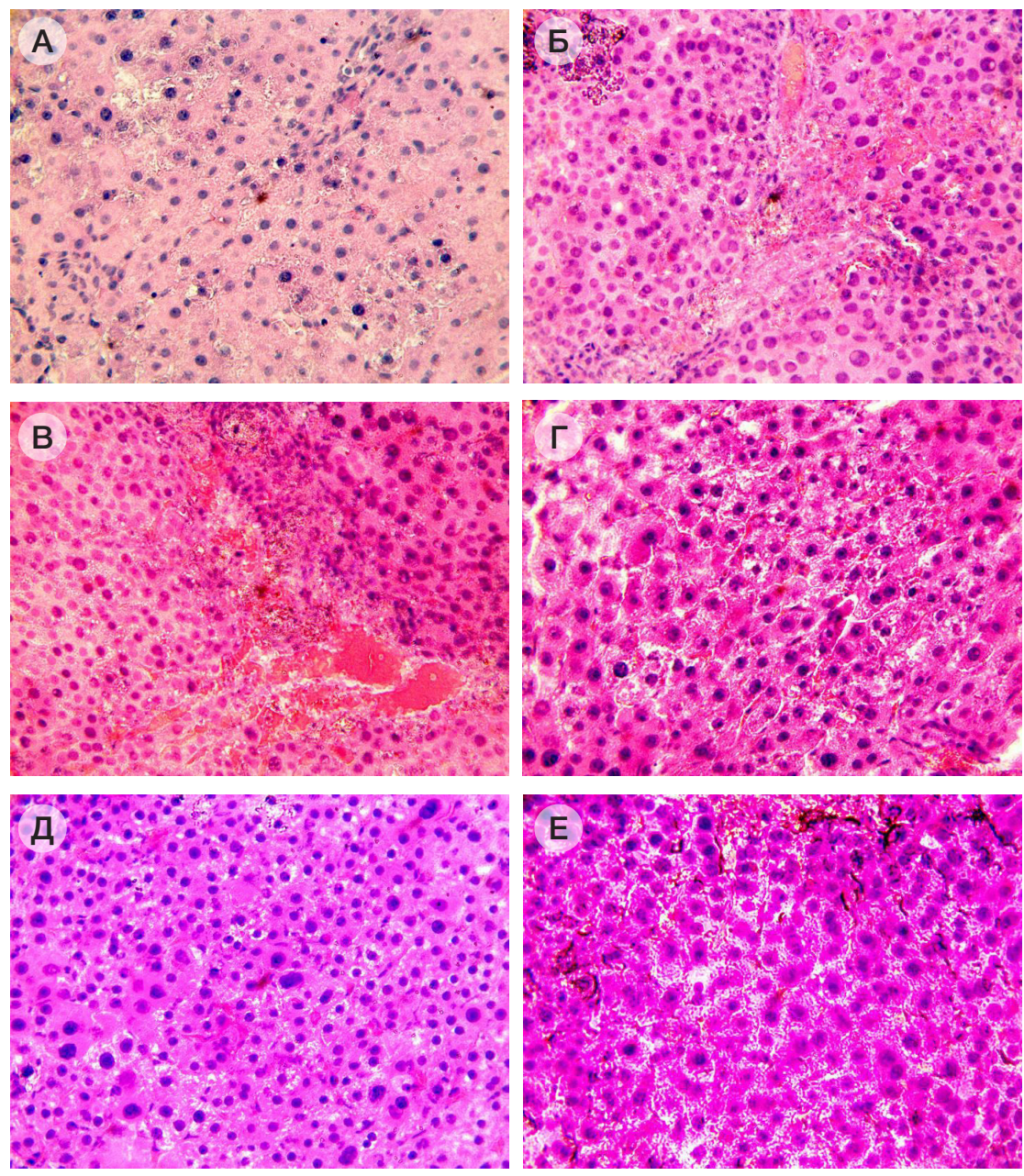

Рис. 3. Микрофотографии срезов печени животных экспериментальных групп, окрашенных гематокислином-эозином. А. Интактная группа (1). Б, В. Контрольная группа (2). Г. Экспериментальная группа (3). Д. Экспериментальная группа (4). Е. Экспериментальная группа (5). Увеличение ×400 
РСВ, основанный на его мощном антиоксидантном действии. Относительно эффектов ДГМ и ПС в модели индукции токсического гепатита у лабораторных животных литературных данных нет. Существуют лишь указания на проапоптическое действие ДГМ на клетки HepG2 гепатоцеллюлярной карциномы [26]. Учитывая высокую биологическую активность этих полисенолов в различных моделях заболеваний, можно предположить, что исследованное нами защитное действие ДГМ и ПС при ТАА-индуцированной гепатопатологии также может быть основано на их мощном антиоксидантном потенциале.

В работе [27] показано, что диосцин (сапонин из диоскореи японской Dioscorea nipponica Makino), подобно исследованным нами полифенолам, ослабляет гепатотоксичность ТАА, увеличивая содержание в клетках печени глутатиона и активность фрерментов антиоксидантной защиты глутатионпероксидазы и суперкосиддисмутазы, снижая содержание малонового диальдегида. Введение животным диосцина увеличивало экспрессию FXR и p-AMPKa, а также Nrf2, HO-1, NQO-1 и GCLM. Напротив, содержание в клетках печени мРНК провоспалительных факторов NF-кB (p65), ICAM 1, HMGB1, COX-2, TNF $\alpha$, IL1 $\beta$ и IL6 под воздействием введения диосцина снижалось, что, по мнению авторов, является доказательством способности этого природного соединения подавлять гепатотоксичность TAA за счет ослабления работы сигнального пути FXR/AMPK в гепатоцитах.

\section{ВЫВОДЬ}

Проведенные исследования показали, что природные полифенолы класса дигидрофлавонолов (ДГМ) и стильбенов (РСВ и ПС) оказывают положительное воздействие на функции печени в модели экспериментального токсического гепатоза и могут быть рассмотрены в качестве потенциальных гепатопротекторов.

\section{Литература}

1. Li S, Tan HY, Wang N, Cheung F, Hong M, Feng Y. The potential and action mechanism of polyphenols in the treatment of liver diseases. Oxid Med Cell Longev. 2018; 8394818. DOI: 10.1155/2018/8394818.

2. Raff E, Singal AK. Optimal management of alcoholic hepatitis. Minerva Gastroenterol Dietol. 2014; 60 (1): 25-38.

3. Riggio O, Ridola L, Pasquale C. World J Gastrointest Pharmacol Ther Hepatic encephalopathy therapy: An overview. 2010; 1 (2): 54-63.

4. Neuschwander-Tetri BA. Non-alcoholic fatty liver disease. BMC Med. 2017; 15 (1): 45

5. Popov VB, Lim JK. Treatment of nonalcoholic fatty liver disease: The role of medical, surgical, and endoscopic weight loss. J Clin Transl Hepatol. 2015; 3 (3): 230-38.

6. Hong M, Li S, Tan H, Wang N, Tsao SW, Feng Y. Current status of herbal medicines in chronic liver disease therapy: the biological effects, molecular targets and future prospects. Int J Mol Sci. 2015; 16 (12): 28705-45.

7. Festi D, Vestito A, Mazzella G, Roda E, Colecchia A. Management of hepatic encephalopathy: focus on antibiotic therapy. Digestion. 2006; 73 (Suppl. 1): 94-101.

8. Malaguarnera M, Gargante MP, Malaguarnera G, Salmeri M, Mastrojeni S, Rampello L, et al. Bifidobacterium combined with fructo-oligosaccharide versus lactulose in the treatment of patients with hepatic encephalopathy. Eur J Gastroenterol Hepatol. 2010; 22 (2): 199-206

9. Efrati C, Masini A, Merli M, Valeriano V, Riggio O. Effect of sodium benzoate on blood ammonia response to oral glutamine challenge in cirrhotic patients: a note of caution. Am J Gastroenterol. 2000; 95 (12): 3574-78.

10. Plauth M, Cabre E, Riggio O, Assis-Camilo M, Pirlich M, Kondrup J, et al. ESPEN guidelines on enteral nutrition: liver disease. Clin Nutr. 2006; 25 (2): 285-94.

11. Wong VW, Singal AK. Emerging medical therapies for nonalcoholic fatty liver disease and for alcoholic hepatitis. Trans Gastroenterol Hepatol. 2019; (4): 53.

12. Минушкин О. Н., Масловский Л. В., Букшук А. А. Применение гепатопротекторов в клинической практике. Журнал неврологии и психиатрии им. С. С. Корсакова. 2012; 10 (2): 67-72.

13. Теплова В. В., Исакова Е. П., Кляйн О. И., Дергачева Д. И., Гесслер Н. Н., Дерябина Ю. И. Природные полифенолы: биологическая активность, фармакологический потенциал, пути метаболической инженерии (Обзор). Прикладная биохимия и микробиология. 2018; 54 (3): 215-35.

14. Quideau S, Deffieux D, Douat-Casassus C, Pouysegu L. Plant polyphenols: chemical properties, biological activities, and synthesis. Angewandte Chemie Intern Edition. 2011; 50 (3): 586-621.
15. Ma JQ, Li Z, Xie WR, Liu CM, Liu SS. Quercetin protects mouse liver against CCl4-induced inflammation by the TLR2/4 and MAPK/NF-kB pathway. Intern Immunopharm. 2014; 28 (1): 531-39.

16. Ma JQ, Ding J, Zhao H, Liu CM. Puerarin attenuates carbon tetrachloride-induced liver oxidative stress and hyperlipidaemia in mouse by JNK/c-Jun/CYP7A1 pathway. Basic Clin Pharmacol Toxicol. 2014; 115 (5): 389-95.

17. Liao CC, Day YJ, Lee HC, Liou JT, Chou AH, Liu FC. ERK signaling pathway plays a key role in baicalin protection against acetaminophen-induced liver injury. Am J Chinese Med. 2017; 45 (1): 105-21.

18. Wallace MC, Hamesch $\mathrm{K}$, Lunova M, Kim $\mathrm{Y}$, Weiskirchen R, Strnad $\mathrm{P}$, et al. Standard operating procedures in experimental liver research: thioacetamide model in mice and rats. Laboratory Animals. 2015; 49 (S1): 21-9.

19. Xie $Y$, Wang $G$, Wang $H$, Yao $X$, Jiang $S$, Kang $A$, et al. Cytochrome P450 dysregulations in thioacetamide-induced liver cirrhosis in rats and the counteracting effects of hepatoprotective agents. Drug Metabolism and Disposition. 2012; 40 (4): 796-802.

20. Ingawale DK, Mandlik SK, Naik SR. Models of hepatotoxicity and the underlying cellular, biochemical and immunological mechanism(s): a critical discussion. Environ Toxicol Pharmacol. 2014; 37 (1): 118-33.

21. Seif El-Din SH, El-Lakkany NM, Salem MB, Hammam OA, Saleh S, Botros SS. Resveratrol mitigates hepatic injury in rats by regulating oxidative stress, nuclear factorkappa B, and apoptosis. J Advanc Pharmaceut Technol Res. 2016; 7 (3): 99-104

22. Франк Г. А., Мальков П. Г., редакторы. 101 шаг на пути к успеху в гистологии. Leica Microsystems Vetzlar, Germany, 2012; 136 C

23. Манских В. Н. Патоморфология лабораторной мыши. М.: BAKO, 2018; $224 \mathrm{c}$.

24. Kang MC, Kang SM, Ahn G, Kim KN, Kang N, Samarakoon KW et al. Protective effect of a marine polyphenol, dieckol against carbon tetrachlorideinduced acute liver damage in mouse. Environ Toxicol Pharmacol. 2013; 35 (3): 517-23.

25. Kim DW, Cho HI, Kim KM, Kim YS. Isorhamnetin-3-O-galactoside protects against $\mathrm{CCl} 4$-induced hepatic injury in mice. Biomolecules Therapeutics. 2012; 20 (4): 406-12.

26. Huang $X$, Lian $T$, Guan $X$, Liu B, Hao $S$, Zhang J, et al. Dihydromyricetin reduces TGF- $\beta$ via P53 activation-dependent mechanism in hepatocellular carcinoma HepG2 cells. Protein Pept Lett. 2017; 24 (5): 419-24.

27. Zheng L, Yin L, Xu L, Qi Y, Li H, Xu Y, et al. Protective effect of dioscin against thioacetamide-induced acute liver injury via FXR/ AMPK signaling pathway in vivo. Biomed Pharmacother. 2018; (97): 481-8. DOI: 10.1016/..biopha.2017.10.153. 


\section{References}

1. Li S, Tan HY, Wang N, Cheung F, Hong M, Feng Y. The potentia and action mechanism of polyphenols in the treatment of liver diseases. Oxid Med Cell Longev. 2018; 8394818. DOI: 10.1155/2018/8394818.

2. Raff E, Singal AK. Optimal management of alcoholic hepatitis. Minerva Gastroenterol Dietol. 2014; 60 (1): 25-38.

3. Riggio O, Ridola L, Pasquale C. World J Gastrointest Pharmaco Ther Hepatic encephalopathy therapy: An overview. 2010; 1 (2): 54-63.

4. Neuschwander-Tetri BA. Non-alcoholic fatty liver disease. BMC Med. 2017; 15 (1): 45

5. Popov VB, Lim JK. Treatment of nonalcoholic fatty liver disease: The role of medical, surgical, and endoscopic weight loss. J Clin Transl Hepatol. 2015; 3 (3): 230-38.

6. Hong M, Li S, Tan H, Wang N, Tsao SW, Feng Y. Current status of herbal medicines in chronic liver disease therapy: the biological effects, molecular targets and future prospects. Int J Mol Sci. 2015; 16 (12): 28705-45

7. Festi D, Vestito A, Mazzella G, Roda E, Colecchia A. Management of hepatic encephalopathy: focus on antibiotic therapy. Digestion. 2006; 73 (Suppl. 1): 94-101.

8. Malaguarnera M, Gargante MP, Malaguarnera G, Salmeri M, Mastrojeni S, Rampello L, et al. Bifidobacterium combined with fructo-oligosaccharide versus lactulose in the treatment of patients with hepatic encephalopathy. Eur J Gastroenterol Hepatol. 2010; 22 (2): 199-206.

9. Efrati C, Masini A, Merli M, Valeriano V, Riggio O. Effect of sodium benzoate on blood ammonia response to oral glutamine challenge in cirrhotic patients: a note of caution. Am J Gastroenterol. 2000; 95 (12): 3574-78

10. Plauth M, Cabre E, Riggio O, Assis-Camilo M, Pirlich M, Kondrup J, et al. ESPEN guidelines on enteral nutrition: liver disease. Clin Nutr. 2006; 25 (2): 285-94.

11. Wong VW, Singal AK. Emerging medical therapies for nonalcoholic fatty liver disease and for alcoholic hepatitis. Transl Gastroenterol Hepatol. 2019; (4): 53.

12. Minushkin ON, Maslovsky LV, Bukshuk AA. The use of hepatic protectors in clinical practice. Zh Nevrol Psikhiatr Im SS Korsakova. 2012; 10 (2): 67-72.

13. Teplova W, Isakova EP, Klein OI, Dergacheva DI, Gessler NN, Deryabina YI. Natural Polyphenols: Biological Activity, Pharmacological Potential, Means of Metabolic Engineering (Review). Applied Biochemistry and Microbiology. 2018; 54 (3): 221-37.

14. Quideau S, Deffieux D, Douat-Casassus C, Pouysegu L. Plant polyphenols: chemical properties, biological activities, and synthesis. Angewandte Chemie Intern Edition. 2011; 50 (3): 586-621.

15. Ma JQ, Li Z, Xie WR, Liu CM, Liu SS. Quercetin protects mouse liver against CCl4-induced inflammation by the TLR2/4 and MAPK/NF-кB pathway. Intern Immunopharm. 2014; 28 (1): 531-39.

16. Ma JQ, Ding J, Zhao H, Liu CM. Puerarin attenuates carbon tetrachloride-induced liver oxidative stress and hyperlipidaemia in mouse by JNK/c-Jun/CYP7A1 pathway. Basic Clin Pharmacol Toxicol. 2014; 115 (5): 389-95

17. Liao CC, Day YJ, Lee HC, Liou JT, Chou AH, Liu FC. ERK signaling pathway plays a key role in baicalin protection against acetaminophen-induced liver injury. Am J Chinese Med. 2017; 45 (1): 105-21.

18. Wallace MC, Hamesch K, Lunova M, Kim Y, Weiskirchen R, Strnad $P$, et al. Standard operating procedures in experimental liver research: thioacetamide model in mice and rats. Laboratory Animals. 2015; 49 (S1): 21-9.

19. Xie $Y$, Wang $G$, Wang $H$, Yao $X$, Jiang $S$, Kang $A$, et al Cytochrome P450 dysregulations in thioacetamide-induced liver cirrhosis in rats and the counteracting effects of hepatoprotective agents. Drug Metabolism and Disposition. 2012; 40 (4): 796-802.

20. Ingawale DK, Mandlik SK, Naik SR. Models of hepatotoxicity and the underlying cellular, biochemical and immunological mechanism(s): a critical discussion. Environ Toxicol Pharmacol. 2014; 37 (1): 118-33.

21. Seif El-Din SH, El-Lakkany NM, Salem MB, Hammam OA, Saleh S, Botros SS. Resveratrol mitigates hepatic injury in rats by regulating oxidative stress, nuclear factorkappa B, and apoptosis. J Advanc Pharmaceut Technol Res. 2016; 7 (3): 99-104.

22. Frank GA, Malkov PG, редакторы. 101 shag na puti k uspekhu v gistologii. Leica Microsystems Vetzlar, Germany, 2012; 136 c. Russisn.

23. Kang MC, Kang SM, Ahn G, Kim KN, Kang N, Samarakoon KW, et al. Protective effect of a marine polyphenol, dieckol against carbon tetrachlorideinduced acute liver damage in mouse. Environ Toxicol Pharmacol. 2013; 35 (3): 517-23.

24. Kang MC, Kang SM, Ahn G, Kim KN, Kang N, Samarakoon KW, et al. Protective effect of a marine polyphenol, dieckol against carbon tetrachlorideinduced acute liver damage in mouse. Environ Toxicol Pharmacol. 2013; 35 (3): 517-23.

25. Kim DW, Cho HI, Kim KM, Kim YS. Isorhamnetin-3-O-galactoside protects against $\mathrm{CCl} 4$-induced hepatic injury in mice. Biomolecules Therapeutics. 2012; 20 (4): 406-12.

26. Huang $X$, Lian $T$, Guan X, Liu B, Hao S, Zhang J, et al. Dihydromyricetin reduces TGF- $\beta$ via P53 activation-dependent mechanism in hepatocellular carcinoma HepG2 cells. Protein Pept Lett. 2017; 24 (5): 419-24.

27. Zheng L, Yin L, Xu L, Qi Y, Li H, Xu Y, et al. Protective effect of dioscin against thioacetamide-induced acute liver injury via FXR/ AMPK signaling pathway in vivo. Biomed Pharmacother. 2018; (97): 481-8. DOl: 10.1016/j.biopha.2017.10.153. 